\title{
Paul's Teaching on the Pneumatika in 1 Corinthians 12-14
}

Prophecy as the Paradigm of ta Charismata ta Meizona for the Future-Oriented Ekklēsia

[Die Lehre des Paulus über die Pneumatika im 1. Korinther 12-14. Prophezeiung als Paradigma von ta Charismata ta Meizona für die zukunftsorientierte Ekklēsia.]

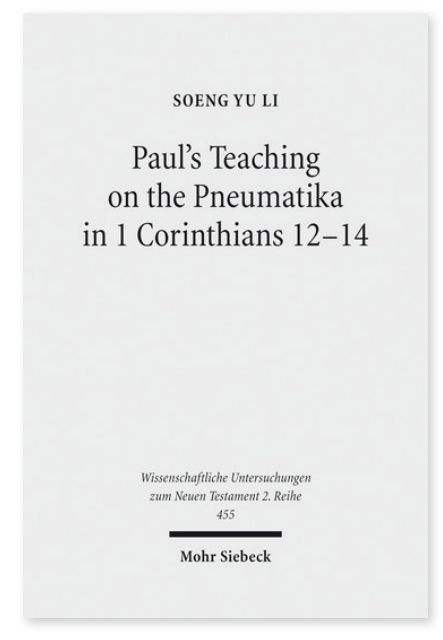

2017. XX, 543 Seiten. WUNT II 455

ISBN 978-3-16-155460-5

DOI 10.1628/978-3-16-155460-5

eBook PDF 129,00€

ISBN 978-3-16-155146-8

fadengeheftete Broschur 129,00€
Veröffentlicht auf Englisch.

Soeng Yu Li untersucht in dieser Studie das paulinische Verständnis der Charismata in 1. Korinther 12-14 und fragt, weshalb Paulus sich in 1. Korinther 14 auf das Charisma der Prophezeiung konzentriert. Nachdem sie gezeigt hat, dass die semantische Beziehung zwischen Charismata und Pneumatika als Meronymie zu verstehen ist, bietet die Autorin eine Exegese des 1. Korinther 12-14 aus meronymischer Perspektive. In 1. Korinther 12-14 lehrt Paulus über das Thema Pneumatika im Sinne von Dingen, die das Leben der Pneumatikoi charakterisieren. Paulus lehrt die Korinther, dass sowohl ihr Verhalten als auch der Gebrauch der innen zugeteilten Charismata als Pneumatikoi von Agapē geprägt sein muss. Nur so können sie die Ekklēsia im Hier und Jetzt und für die versprochene eschatologische Zukunft aufbauen. Um seine Lehre zu veranschaulichen, nutzt Paulus Prophezeiung als das Paradigma für ta Charismata ta Meizona der versammelten Ekklēsia, die in der zukunftsorientierten Gegenwart lebt.

Soeng Yu Li Born 1980; studied sinology and theology; 2016 PhD; currently researcher for New Testament exegesis at the Faculty of Theology and Religious Studies, Katholieke Universiteit Leuven, Belgium.

\section{Jetzt bestellen:}

https://mohrsiebeck.com/buch/pauls-teaching-on-the-pneumatika-in-1-corinthians-12-14-9783161554605?no_cache=1 order@mohrsiebeck.com

Telefon: $+49(0) 7071-923-17$

Telefax: +49 (0)7071-51104 